(2) Open Access Full Text Article

\title{
Learnings from Health Behavioural Survey Practices in France and Belgium During the First COVID-19 Stay-at-Home Order
}

This article was published in the following Dove Press journal: Patient Preference and Adherence

\author{
Benoit Pétré \\ Delphine Kirkove' \\ Vincent de Andrade (iD) ${ }^{2}$ \\ Cyril Crozet $\mathbb{D}^{2}$ \\ Daniela Toro-Arrocet ID $^{2}$ \\ Aurore Margat (iD ${ }^{2}$ \\ Rémi Gagnayre $\mathbb{D}^{2}$ \\ 'Department of Public Health, University \\ of Liege, Liège, Belgium; ${ }^{2}$ Education and \\ Health Practices Laboratory, UR 34I2, \\ UFR Santé Médecine Biologie Humaine, \\ Sorbonne Paris-Nord University, Bobigny, \\ France
}

Correspondence: Benoit Pétré

Department of Public Health, University

of Liège, Quartier Hôpital, Avenue

Hippocrate I3 (B23), Liège, 4000, Belgium

Tel +32 43662505

Email benoit.petre@uliege.be

\begin{abstract}
The COVID-19 pandemic has compelled public authorities to establish preventive measures involving individual behaviour modification strategies (mask-wearing, social distancing, etc.) with a view to community protection. In this context, documenting people's behaviour changes, the impact of public health measures, and individuals' knowledge, motivations, and beliefs - even their perception of how the crisis is being managed - is essential for understanding the experience of the population and adapting the management approach accordingly. This article presents findings and lessons on how to monitor a population's behaviour during a crisis, obtained by reviewing forty-five surveys conducted in Belgium and France during the first Covid-19 stay-at-home order, from April to May 2020. The central message is to argue that the citizens' role in this type of survey - and in managing the crisis, more generally - should be reconsidered by thinking of them as true health partners and members of a community that could be mobilised to help.
\end{abstract}

Keywords: pandemic, covid 19, community monitoring, preventive health behavior

The COVID-19 pandemic requires strenuous efforts to modify individual behaviours with the aim of achieving population-level prevention. ${ }^{1}$ Understanding people's experience is thus essential for managing this unprecedented public health crisis. ${ }^{2}$ The World Health Organisation has encouraged its Member States to conduct surveys to monitor the knowledge and behaviour of their populace with regard to pandemic response measures. The aim of such surveys is to "inform government decisions, shape communications and guide the planning of measures". ${ }^{3}$ This call for monitoring was heard and resulted in numerous surveys being conducted across the globe. ${ }^{4}$

Here we present and discuss the preliminary results from a study aimed at describing those surveys monitoring individuals' experience of the crisis in terms of prevention message uptake (comprehension, motivation, and attitudes), perception of current and future crisis management measures, and population behaviours and their impact. The study focused on the first stay-at-home period in Belgium and France, in April and May 2020. These two countries were chosen so that the analysis would involve relatively similar sociocultural and health policy contexts.

Surveys were identified and assembled using the search string and keywords "Covid 19" AND ("survey*” OR “questionnaire") via: 
- Tools for the general public such as Google News (which offers email alerts) $(\mathrm{n}=35)$

- Social networks such as Twitter $(\mathrm{n}=7)$

- Information from authors' co-workers $(\mathrm{n}=15)$.

The assembled surveys were saved at an online file hosting site (Imgur). Two researchers independently checked identified surveys for relevancy. Twelve surveys were excluded with reason: out of the scope of the study or neither in French nor English.

Surveys were analysed with a reading grid containing the WHO's methodological recommendations, ${ }^{3}$ supplemented by data from the analysis. The researchers read the content of surveys in order to familiarise themselves with the information and identify emergent themes. The final list of complementary themes was defined through consensus among the researchers. Then, analysis process was distributed among the team: for each survey, two researchers independently extracted and classified all the content that corresponded to a theme of the analysis grid. In case of discrepancy, a third researcher help to decide which information is to keep and how to rank it.

Figure 1 shows the preliminary results based on our final selection of forty-five surveys.

The principal lessons from those results and recommendations for improving population monitoring surveys are as follows:

- Seek to balance the contents being investigated. The results show that surveys tend to focus on those that look at the impact of prevention measures instead of those that look at comprehension of prevention measures and comprehension of compliance-related factors $\rightarrow$ monitoring the impact of the crisis should not short-circuit verification of the comprehensibility of the situation or adherence or its explanatory factors among the citizen. ${ }^{5}$

- Recognise the respondents as true information producers. Little citizen participation in study design, limited investigation into how citizens see a way out of the crisis, limited practicability of surveys due to their length, and a lack of help in completing the surveys compromises survey acceptance by participants treated simply as respondents and not as true health actors $\rightarrow$ citizen engagement is a crucial element in the effort to guide management of the crisis. $^{6}$

- Service to the community must be the first priority. Failing to clearly explain how results will be used, choosing themes that prioritise impact, and having too many questions raises questions about some survey designers' ultimate goal $\rightarrow$ from an ethical standpoint, the primary aim of a monitoring effort should be to inform policymakers on appropriate public health strategies. How the results will be used should be clearly stated. Opportunities for scientific research and exploitation are secondary to that aim and should not contaminate the surveys in any way.

- Centralise studies to ensure sharing and completeness. The partial overlap among the studies in terms of audience and contents, and the difficulty we encountered in accessing surveys for review, demonstrates the need to share ongoing studies within the

- $80 \%$ of the surveys were conducted by university teams and $9 \%$ by public research institutions. Only $5 \%$ were conducted by patient organisations.

- Fewer than $50 \%$ of the studies specified the target population.

- $24 \%$ of the surveys clearly stated how the results would be used.

- $41 \%$ of the surveys looked at the impact of stay-at-home orders on the population, and $26 \%$ at adherence to those measures. The impact could be emotional, behavioural, social, and/or professional. Adherence to the measures could involve self-efficacy, information perception, and/or perceived risk.

- $17 \%$ of the surveys investigated the comprehension or knowledge of such measures.

- $16 \%$ of the surveys asked participants about their perception of lifting stay-at-home restrictions.

- The surveys varied widely in the time needed to complete them; they ranged from 7 (minimum) to 278 (maximum) items to answer. The mean was 85 questions per survey. When given, the estimated time needed ranged from 10 minutes (minimum) to 60 minutes (maximum). The mean was 19.53 minutes per survey.

- $13 \%$ of the surveys offered help in filling them out (via more detailed instructions).

Figure I Observations regarding monitoring studies on prevention message uptake, behaviour, and impact on the population during pandemic stay-at-home orders (April and May 2020): the case of France and Belgium. 
scientific community $\rightarrow$ these findings show that during pandemics, studies should be centralised (via a centralised platform) to allow a better joint approach to monitoring at the national, or even international, level. ${ }^{3,4}$

Managing a public health crisis like COVID-19 requires full citizen participation, as well as motivation to maintain and own protective behaviours over the long term, despite pandemic fatigue. ${ }^{7}$ In light of survey design and administration, our results argue that the citizens' role in monitoring the crisis should be reconsidered, and that they be thought of as true health partners and members of a community that could be mobilized to help manage it.

\section{Disclosure}

The authors report no conflicts of interest in this work. Both Benoit Pétré and Delphine Kirkove are members of Be.Hive, the Belgian French-speaking Interdisciplinarity Primary Care Chair. The chair is supported by Fund De Coninck. The Fund Dr Daniël De Coninck is managed by the King Baudouin Foundation.

\section{References}

1. Van den Broucke S. Editorial: why health promotion matters to the COVID-19 pandemic, and vice versa. Health Promot Int. 2020;35(2): daaa042. doi:10.1093/heapro/daaa042
2. Santé Publique France. COVID-19: point épidémiologique du 9 juillet 2020, une enquête pour suivre l'évolution des comportements et de la santé mentale pendant l'épidémie [Internet]. Etudes et enquêtes; 2020. [Epidemiological update of 9 July 2020, a survey to monitor changes in behaviour and mental health during the epidemic [Internet]. Studies and surveys]. Available from: https://www.santepu bliquefrance.fr/etudes-et-enquetes/covid-19-une-enquete-pour-suivre -1-evolution-des-comportements-et-de-la-sante-mentale-pendant-1-epi demie. Accessed December 20, 2020. French.

3. WHO Regional Office for Europe. Survey tool and guidance: rapid, simple, flexible behavioural insights on COVID-19. Monitoring knowledge, risk perceptions, preventive behaviours and trust to inform pandemic outbreak response [Internet]; 2020. Available from: http://it.ubc.ca/services/teaching-learning-tools/survey-tool. Accessed December 20, 2020.

4. Glasziou PP, Sanders S, Hoffmann T. Waste in covid-19 research. BMJ. 2020;369:1-2. doi:10.1136/bmj.m1847

5. Michie S, Rubin GJ, Amlot R. Behavioural science must be at the heart of the public health response to covid-19. BMJ Opin. 2020. Available from: https://blogs.bmj.com/bmj/2020/02/28/behaviouralscience-must-be-at-the-heart-of-the-public-health-response-to-covid -19/. Accessed December 20, 2020.

6. Yardley L, Richard A, Rice C, Robin C, Michie S. How can we involve communities in managing the covid-19 pandemic? $B M J$ Opin. 2020. Available from: https://blogs.bmj.com/bmj/2020/03/17/ how-can-we-involve-communities-in-managing-the-covid-19pandemic/. Accessed December 20, 2020.

7. WHO Regional Office for Europe. Pandemic fatigue: reinvigorating the public to prevent COVID-19. Policy framework for supporting pandemic prevention and management. Copenhagen; 2020. Available from: https://apps.who.int/iris/bitstream/handle/10665/335820/WHOEURO-2020-1160-40906-55390-eng.pdf. Accessed December 20, 2020.
Patient Preference and Adherence

\section{Publish your work in this journal}

Patient Preference and Adherence is an international, peer-reviewed, open access journal that focusing on the growing importance of patient preference and adherence throughout the therapeutic continuum. Patient satisfaction, acceptability, quality of life, compliance, persistence and their role in developing new therapeutic modalities and compounds to optimize clinical outcomes for existing disease

\section{Dovepress}

states are major areas of interest for the journal. This journal has been accepted for indexing on PubMed Central. The manuscript management system is completely online and includes a very quick and fair peer-review system, which is all easy to use. Visit http:// www.dovepress.com/testimonials.php to read real quotes from published authors. 